DOI: https://doi.org/10.24867/11FA19Pajic

\title{
IDEJNI PROJEKAT CENTRA ZA SCENSKE UMETNOSTI U BLOKU 39, KULTURNI IDENTITET NOVOG BEOGRADA
}

\section{CONCEPT DESIGN OF THE CENTER FOR PERFORMING ARTS IN BLOCK 39, CULTURAL IDENTITY OF NEW BELGRADE}

\author{
Mladen Pajić, Fakultet tehničkih nauka, Novi Sad
}

\begin{abstract}
Oblast - ARHITEKTURA i URBANIZAM
Kratak saržaj - Ritam pokreta, ritam u arhitekturi, ritam u scenskom dizajnu, materijalizaciji. Ritam kao glavna reč ovog rada. Rad se bavi kulturnim identitom Novog Beograda $i$ proučavanjem arhitekture kulturnih javnih objekata sa osvrtom na nedostatak kulturnog razvoja $u$ Srbiji. Projekat podrazumeva idejno rešenje Centra za scenske umetnosti u Bloku 39 u Novom Beogradu, sa istorijskim osvrtom na scensku umetnost u Srbiji, kao i konstruktivizam na globalnom i lokalnom nivou.
\end{abstract}

Ključne reči: Scenska umetnost, kultura, teatar, scena, konstruktivizam, hi tech arhitektura

\begin{abstract}
Abstarct - Rhythm of movement, rhythm in architecture, rhythm in stage design, materialization. Rhythm as the main word of this paper. The paper deals with the cultural identity of New Belgrade and the study of the architecture of cultural public buildings with reference to the lack of cultural development in Serbia. The project includes the conceptual design of the Center for Performing Arts in Block 39 in New Belgrade, with a historical overview of performing arts in Serbia, as well as constructivism at the global and local level.
\end{abstract}

Key words: performing arts, culture, theater, stage, constructivism, hi tech arhitecture

\section{UVOD}

U ovom radu ću se baviti multimedijalnim salama, odnosno kulturnim centrima kao arhitektonskim sublimatima scenske i kulturne arhitekture uopšte. Nedostatak kulturnih centara u Srbiji je veliki problem, kao i nedostatak brige o kulturi. Novi Beograd kao najveća opština $u$ Srbiji, je pravi primer tog tumačenja.

Novi Beograd kao poslovni centar grada, sa sve više ljudi koji njime svakodnevno kruže ima jedan bioskop „Fontana“, jedno dečije pozorište (koje se nalazi tu umesto starog bioskopa „Jugoslavija“), kongresni i kulturni centar „Sava Centar“ i par centara kulture pri studentskom gradu kao i biblioteka sa neprofilisanim arhitektonskim ciljem. Bioskope u tržnim centrima izostavljam iz pomenute liste, zbog razlike u kulturnom pristupu razlitičitih ustanova kulturne i komercijalne sadržine.

\section{NAPOMENA:}

Ovaj rad proistekao je iz master rada čiji mentor je bila dr Jelena Atanacković Jeličić.
Po meni svi glavni gradovi, epicentri kulture Evrope i Sveta ne podilaze tim tendencijama da se kulturni sadržaj (bioskopi uglavnom) smeste u komercijalne sadržaje, uz nadu da će ostvariti veći prihod. Naravno moj utopijski stil pisanja se kosi sa surovom stvarnošću ali ipak ima i svetlih primera u današnjoj arhitekturi. Grade se koncertne hale, multimedijalni centri, centri scenskih umetnosti koji poseduju sve te sadržaje na jednom mestu.

\section{SCENA}

Srce bilo koje predstave je scena, mesto izvođenja. Scenu obuhvata prostor za sedenje i bina. Definicija svih ostalih aktivnosti i prostora unutar objekta odnosi se na aktivnost performansi i scenu, bilo direktno ili indirektno. Objekti publike direktno su povezani u pogledu kapaciteta i pristupa, a posredno i željenog ambijenta i slike koji će se stvoriti. Backstage sadržaji su u direktnoj vezi u pogledu prizora, scenske forme i zahteva za pristup pozornici, a posredno i pomoću prostorije za probe i montaže. Performans je komunikacija, a dramske scene se razlikuju od muzičkih scena prema mediju komunikacije između izvođača i publike.

Drama deluje sa vizuelnom iluzijom, kretanjem, gestikulacijom i artikulacijom izgovorenih reči. Muzika deluje sa zvučnom iluzijom, ritmičkim obrascima, tonskim varijacijama i suptilnim interakcijama zvuka. U performansima uživo komunikacija se prepušta i vidu i sluhu, ali svaka umetnička forma naglašava jedno ili drugo [1].

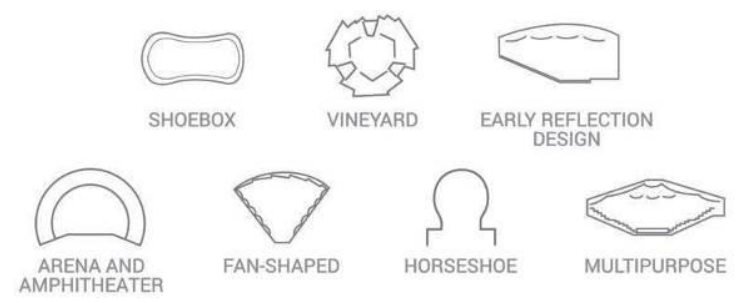

Slika 1. Oblici oblikovanja scene

\section{KONSTRUKTIVIZAM U SRPSKOJ ARHITEKTURI}

U srpskoj arhitekturi druge polovine XX veka prisutno je nekoliko tendencija koje se odnose na primenu savremenih tehnoloških i konstruktivnih rešenja, kao i na upotrebu savremenih materijala. Ove pojave mogu da se podvedu pod nekoliko termina, medju kojima su najkarakterističniji: novi konstruktivizam, hajteh, dekonstruktivizam. Najraniji ali i najznačajniji primer ove arhitekture jeste projekat kompleksa Beogradskog sajma (1954) 
Milorada Pantovića i saradnika, među kojima je značajno pomenuti imena konstruktora Milana Krstića i Branka Žeželja. Bilo je ovo konstruktivno dostignuća vredno svetske pažnje [2].

Spasoje Krunić je projektovao konstrukciju Komandno operativnog centra Sekretarijata unutrašnjih poslova Beograda upotrebom prostorne rešetkaste konstrukcije koja formira celokupnu strukturu arhitektonskog objekta.

Posebno treba napomenuti Centar „Sava“ na Novom Beogradu kao najveći kongresni, kulturni i poslovni centar u našoj zemlji i jedan od najvećih u regionu. Izgradnja Sava centra trajala je tri godine, od 1976. do 1979, a izgrađen je po zamisli arhitekte Stojana Maksimovića koji je bio i šef konstruktorskog tima. Sava Centar predstavlja jedan od bisera našeg konstruktivizma, sa čitljivom arhitekturom, vidljivom konstrukcijom $\mathrm{u}$ enterijeru i dalje najvećom salom za posetioce $u$ zemlji.

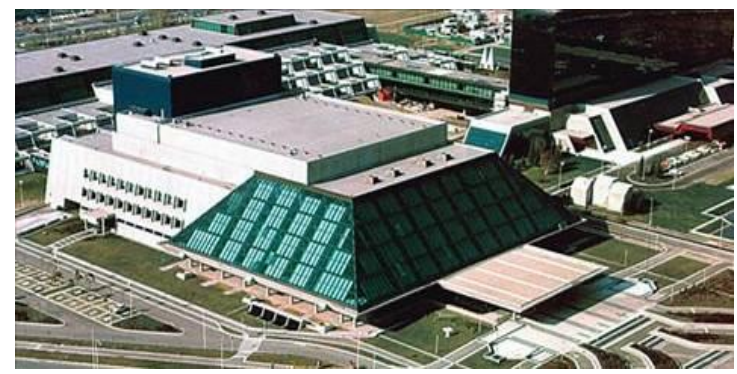

Slika 2. Centar „Sava“

\section{STUDIJE SLUČAJA}

\subsection{Arhitektura Richarda Rogersa}

\section{Pompidou centar, Pariz / NEO Bankside, London / Lloyd's Building, London / 8 Chifley, Sidnej}

Ričard Rodžers je britanski arhitekta rođen u Italiji i jedan od začetnika hi-tech arhitekture. Kao studiju slučaja sam uzeo ne jedan njegov projekat nego čitav njegov opus umetničkih i inženjerskih dela. Zvanično je ove godine otišao u penziju i našao sam za shodno da se njegovi projekti nađu u mojoj studiji slučaja kao velika inspiracija. Izdvojio sam nekoliko njegovih projekata koji su na mene ostavili najjači utisak.

Centar Pompidou je zgrada koja se nalazi u glavnom gradu Francuske, Parizu. Centar Pompidou je građen od 1971. Do 1977. Godine, a dizajniralo ga je nekoliko arhitekata, uključujući italijanskog Renzo Piano i Gianfranco Franchini i britanca Richarda Rogersa. Zgrada je jedan od najboljih primera primene visokotehnološke arhitekture i sadrži složeni spoljni skelet napravljen od šarenih cevi. Sam kostur zgrade i vidna konstrukcija sa spoljne strane, pokazujući sve različite mehaničke i konstrukcione sisteme ne samo da bi ih bilo moguće razumeti, već i da maksimalizuje unutrašnji prostor bez prekida. Različiti sistemi na spoljašnjoj strani zgrade obojeni su različitim bojama kako bi se razlikovale njihove različite uloge.

NEO Bankside, London je stambeni blok zgrada koji leži u srcu londonskog područja Bankside. Karakteristični spoljni sistem za pričvršćivanje paviljona uklonio je potrebu za unutrašnjim strukturnim zidovima i stvorio izuzetno fleksibilne prostore unutar stanova. Betonski okvir, sipan na licu mesta, pruža glavnu potporu zgradi.
Obodni zapor služi za bočnu stabilnost pri opterećenju vetrom, smanjujući potrebu za prozirnim zidovima i omogućavajući veću fleksibilnost za unutrašnje planiranje i servisiranje. Pričvrsni elementi se na svakom trećem spratu spajaju pričvršćenim čvorovima, prenoseći bočne sile primenjene na strukturni okvir opterećenjem vetra na oblogu i na sistem zatezanja [3].

Lloyd's Building, London, fleksibilnost je ključni koncept u dizajnu londonskog Lloid's-a, a obezbeđivanje neprekidnog trgovinskog prostora - poznatog kao The Room - je neophodnost. Iz ove potrebe postavlja se oblik zgrade, raspoređujući sve obnovljive elemente potrebne za komplikovanu poslovnu zgradu do krajnjih dijelova podne ploče, i dajući centralnom planu fleksibilnost da deluje kao prostorno efikasno jedinstveno tržište.

Neophodno održavanje i zamena pokretnih delova mogu se tada prilagoditi bez ometanja svakodnevnog procesa potpisivanja ugovora u The Room-u, a njihovo pozicioniranje daje čitljivost i razmere na fasadi.

8 Chifley, Sidnej je poslovna zgrada vrhunskog kvaliteta u Sidneju, Australija. Šema - razvijena zajedno sa Lippmann Partnership - sastoji se od poslovne zgrade od 30 spratova smeštene u Centralnom poslovnom okrugu (CBD) u Sidneju. Upotreba prefabrikovanih delova i ponavljajućih metoda gradnje izražava arhitekturu i čini postupak gradnje čitljivim, kao i osiguravanje visokokvalitetnih završnih obrada na izloženoj strukturi. Južno službeno jezgro izgrađeno je pomoću betonskog sistema $u$ obliku skoka i uzdiglo se nezavisno od podne strukture kancelarije.

Četiri obodna stuba zgrade - mega stubovi - dovedeni su na lokaciju kao prefabrikovane betonske ljuske, a zatim su postali trajna oplata dok su bili napunjeni montažnim kavezima za ojačanje i betonom na licu mesta [4].

\section{CENTAR ZA SCENSKE UMETNOSTI U BLOKU 39}

Idejni projekat centra za scenske umetnosti koncipiran je kao kulturna oaza Novog Beograda. Novi Beograd kao poslovni centar grada vapi za kulturnim sadržajem. Odgovor na taj nedostatak najveće, opštine u Srbiji, je i ovaj idejni projekat.

Planirani Centar za scenske umetnosti je multimedijalni objekat za sve vrste scenske umetnosti (dramske, muzičke, filmske, plesne). Najvažniji i centralni deo svakog multimedijalnog-kulturnog centra jeste sala. Sala u kojoj se susreću posetioci sa izvođačima. Centralni deo i ovog projekta je sala koju čini sedeći deo na dva nivoa.

Donji nivo, sa 850 sedećih mesta na koji se ulazi sa $\mathrm{P}+1$ nivoa i spušta se na kotu prizemlja +- 0.00 na kojoj se nalazi scena. Stepenicama iz ulaznog hola se ide na glavne ulaze u salu. Na drugom spratu se nalazi galerija sa 250 sedećih mesta. Na svakom nivou ispred ulaza $u$ salu se nalazi kafe-bar za posetioce.

Sala je projektovana dijamantskog oblika u cilju što bolje vidljivosti posetioca ka bini iz svakog dela i što bolje akustičnosti. Akustika sale postiže se spuštenim krovom sale koji služi za što bolje rasprostiranje zvuka po celoj sali. 


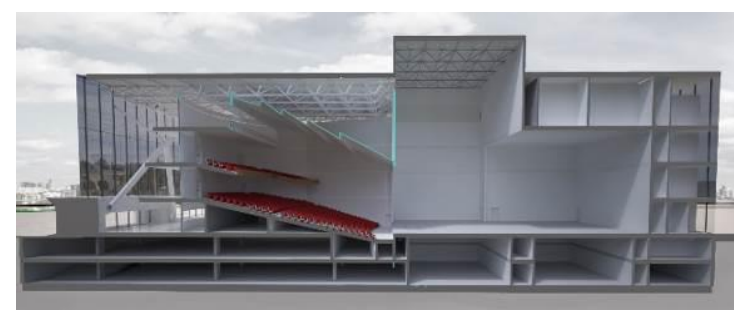

Slika 3. 3D presek objekta

\subsection{Koncept}

Objekat je funkcionalno, dizajnerski, arhitektonski i inženjerski zamišljen kao zvučnik iz čijeg centralnog dela se širi zvuk, dešavanja, vibracije. Dok se iza membrane tj scene nalazi ono što taj zvuk pokreće, odnosno tehnički deo. Tehničke deo objekta se nalazi u drugoj polovini tzv skrivenom delu koji se naizgled ne vidi, koji posetioci i ne primećuju, a najbitniji je za funkcionisanje ovakvog objekta. U tehničkom delu iza scene se nalaze 3 velike sale (2. bočne sale i zadnja sala u kojima se vežbaju nastupi), preko kojih se menja postavka na bini ako su u pitanju dramske predstave. Veliki deo tehničkih prostorija zauzima prostor za odlaganje fundusa, tj kostima i opreme za scenu. Sa zadnje strane objekta se prilazi tovarnim vozilima u magacin.

Monumentalni ulaz od belog betona fragmentira staklenu fasadu i povezuje veliki, otvoreni ulazni hol sa staklenim zidovima fasade. Čelična konstrukcija je izrazito vidljiva, spolja i u unutra, stvarajući čitljivu strukturu objekta. Ceo objekat je izdignut od kote terena i ispred ulaza se formirao otvoren prostor, sličan amfiteatru za cirkulaciju i boravak posetilaca.

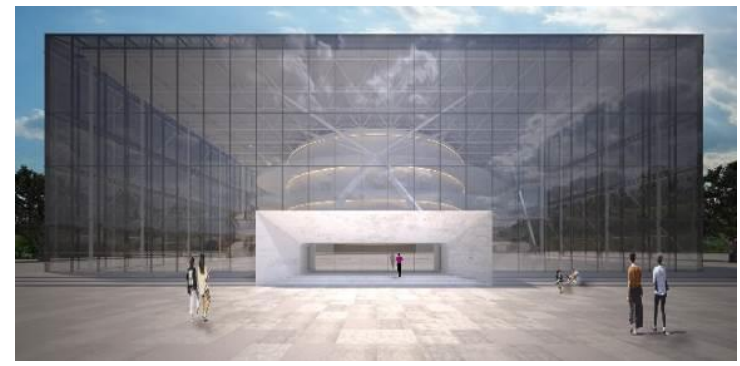

Slika 4. 3D prikaz frontalne fasade

Blizina autoputa je neutralisana drvećem i zelenim rastinjem koje služi kao neka vrsta barijere od buke i ostalih faktore koje blizina autoputa donosi. Parking se nalazi sa zadnje strane objekta kao i ulaz u dva nivoa podzemnih garaža.

Kroz ceo blok prolazi pešačka zona koja spaja Fakultet dramskih umetnosti i ovaj objekat. Prilaz posetilaca je sa svih strana bloka. Pešački sa strane autoputa zbog blizine autobuske stanice i sa najprometnijeg obližnjeg bulevara, dok je prilaz vozila sa zadnje strane kao i sa autoputa.

Objekat je podeljen na nekoliko funkcionalnih celina. Glavna celina je sala sa svim propratnim sadržajima (blagajna, garderoba, bar-restoran), druga celina se nalazi u zatvorenom delu na spratovima tehničkog dela objekta. Jedne stepenice vode ka Sali, dok druge stepenice iz hola vode u muzičku školu, baletsku školu, biblioteku, umetnički šop kao i restoran koji ima pogled na središte bloka i pogled ka mostu na Adi.

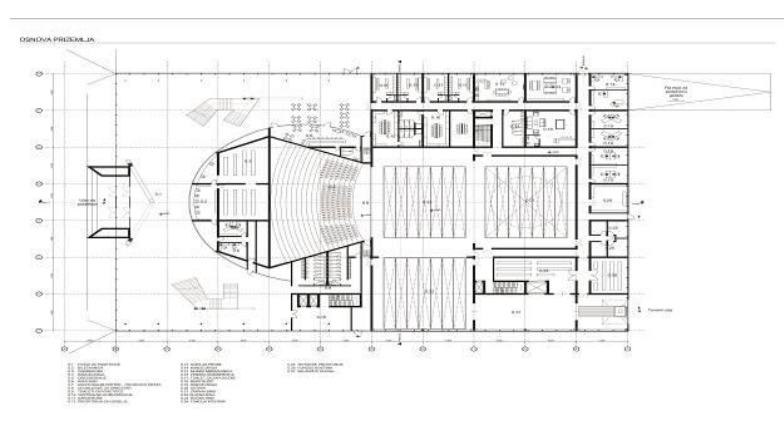

Slika 5. Osnova prizemlja

\subsection{Konstrukcija objekta}

Konstruktivni elementi su veoma bitan deo ovog projekta. Homogenizuju se sa funkcijom objekta i daju mu na masivnosti i sa druge strane na prozračnosti. Na fasadi se nalaze kose sajle koje služe za ukrućenje staklenih fasadnih panela. Dok se sa unutrašnje strane bočnih fasada nalaze stubovi sa perforiranim gredama na koje se oslanja krov i koji takođe nose staklenu fasadu. U ulaznom holu u frontalnom delu se nalaze masivni čelični kosnici tzv drvo, koji drže krov.

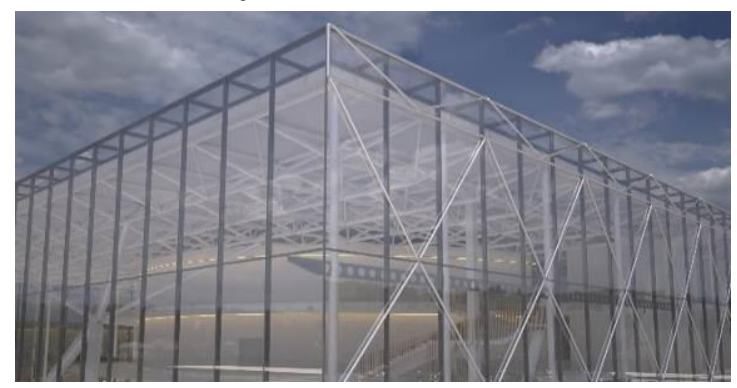

Slika 6. 3D prikaz konstrukcije objekta

Krov je konstruktivno rešen preko rešetke koja je vidljiva u ulaznom holu kao i čitava konstrukcija objekta. Čitljivost konstrukcije daje objektu pored kulturnog i inženjerski značaj. Drugi deo objekta gde se nalaze tehničke prostorije, muzička škola, balet, restoran, biblioteka, je konstuktivno rešen $\mathrm{V}$ kosnicima koji daju i konstruktivni ritam objektu. Stepenice u ulaznom holu se nose preko čeličnog stuba i čeličnog kosnika koji se pružaju od poda do krova i takođe služe nosivosti krova.

\subsection{Fasada objekta}

Prozračna staklena fasada sa konstruktivnim elementima i perforiranim limom u drugom delu objekta odaje utisak ritmičnog objekta. Monumentalni betonski ulaz razbija tu otvorenost i ulaz pomera iz frontalne ravni fasade. Fasada se sastoji od više slojeva. Govorio sam o ritmu projektovanja objekta i na fasadi se to iskazuje takođe. Staklena fasada se prostire duž celog objekta.

U tehničkom delu objekta se preko staklene fasade nalazi perforirani beli lim koji daje određenu privatnost zaposlenima, učenicima škola i posetiocima biblioteke. Jedan od glavnih činilaca fasade je čelična konstrukcija, koja ima i konstruktivnu i estetsku ulogu. Krovna ploča je smaknuta u odnosu na fasadne zidove u ulaznom delu zbog prodora svetlosti u ulazni hol. 


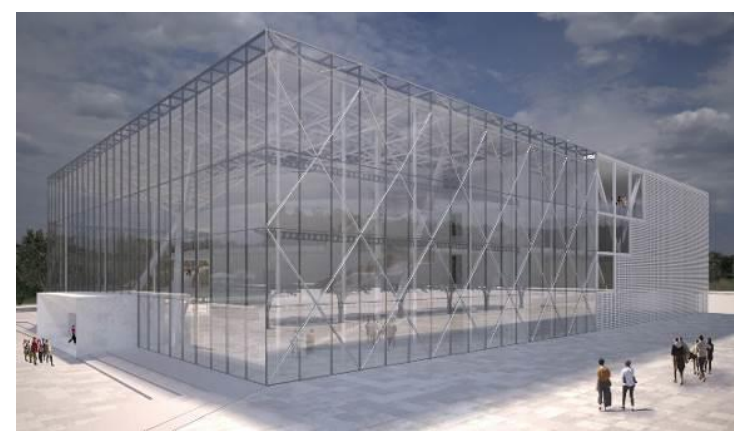

Slika 7.3D prikaz objekta

\section{ZAKLJUČAK}

Ovaj projekat ima za cilj stvaranje zdrave i podsticajne sredine, u kojoj čovek ima mogućnost da razvija svoje društveno, kulturno, profesionalno i socijalno biće. Arhitektura kulturnih objekata je zamrla u Srbiji i ovaj rad je neka vrsta vapaja za promenom i za slobodom. Blok 39 na Novom Beogradu, kao jedna od najboljih lokacija za komercijalni i kulturni sadržaj, trebalo bi da vrati svoju prvobitnu namenu, tj trebalo bi da bude realizovan projekat Kampusa umetničkih fakulteta.

Centar za scenske umetnosti homogenizuje taj projekat i savremenu arhitekturu u najboljem smislu. Novom Beogradu treba kulturni centar koji korespondira sa korisnikom tj posetiocem, otvorenog tipa i okruženje koje će ga privući da tu provede određeno vreme.

Okolina zgrade, otvoreni amfiteatar, blizina fakulteta i susret različitih profila ljudi, generacija čini ovaj objekat čitljivim za sve vrste korisnika.

\section{LITERATURA}

[1] Guyer, J. Paul, An Introduction to Architectural Design, 2014

[2] Maldini, Slobodan, Rečnik arhitektonskog projektovanja, 2009

[3] https://www.rsh-p.com/projects/neo-bankside/

[4] https://www.rsh-p.com/projects/8-chifley/

\section{Kratka biografija:}

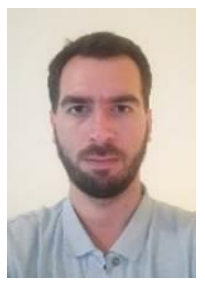

Mladen Pajić rođen je u Tuzli 1990. god. Osnovne akademske studije završio je 2017. god. na univerzitetu „Union - Nikola Tesla“, studijski program arhitektura i urbanizam u Beogradu. Master rad, na master studijama usmerenja Arhitektonsko i urbanističko projektovanje, na Fakultetu tehničkih nauka brani 2020. godine. 